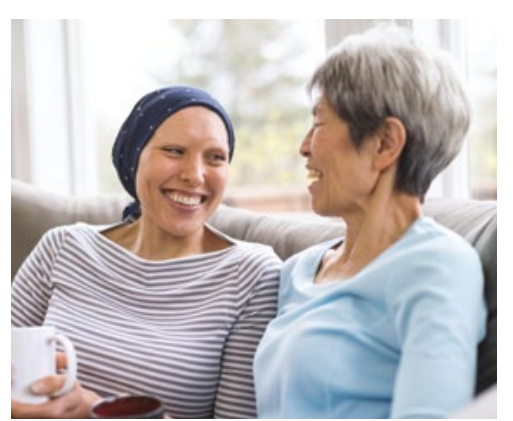

\section{Home-based palliative care}

CPD

Liz Reymond, Greg Parker,

Louisa Gilles, Karen Cooper

\section{Background}

While most people say they would prefer to be cared for and to die at home, this outcome is often not achieved. This represents a service gap that general practitioners (GPs) are optimally positioned to fill.

\section{Objectives}

The aim of this paper is to synthesise existing evidence-based frameworks of palliative care together with other resources, to present a cohesive model of care that GPs can easily systematise to guide high-quality home-based palliative care.

\section{Discussion}

Key clinical processes include advance care planning and development of medical goals of patient care plans and terminal care plans. Three essential elements for high-quality palliative care incorporated into the model include a compassionate GP, the care team and various practical resources. Palliative care sits well within the GP specialist scope of practice. GPs have at their disposal many resources that effectively and efficiently support them in their palliative care practice.
INEVITABLY, everybody dies, and indeed death is a universal health outcome. While most people say they would prefer to be cared for and to die at home, in the majority of cases this outcome is not achieved. ${ }^{1,2}$ The discrepancy between patients' wishes and the realities represents a service gap that general practitioners (GPs) are optimally positioned to fill. The role of the GP assisting with palliative care will become increasingly important into the future. In 2015 about 160,000 people died in Australia, ${ }^{3}$ and this number is likely to double in the next 25 years. ${ }^{2}$ GPs may find palliative care time intensive, but with systematised management, palliative care is satisfying and efficient. This article presents three key clinical processes that GPs can systematise to effectively drive proactive care, and three elements essential to the delivery of high-quality palliative care.

\section{Background}

In Australia, only a small proportion of people die suddenly; most die from conditions with a predictable trajectory, experiencing a prolonged period of disability, frailty and illness and then dying at an older age "with unpredictable timing from a predictably fatal chronic disease'. ${ }^{4}$ In 2015 , the five leading causes of death included coronary heart disease, cerebrovascular disease, dementia, chronic obstructive pulmonary disease and cancer. ${ }^{5,6}$ If death is expected, it can be planned for.
Estimates of the proportion of people who would benefit from palliative care vary from $50 \%$ to $90 \%$ of those who die, suggesting that 80,000-140,000 Australians would benefit from palliative care each year. ${ }^{7,8}$

Palliative care is multifaceted, team-based care that sits well within the GP specialist scope of practice. It is person-centred and family-centred care, provided to a person with active, progressive advanced disease(s) who is expected to die in the short term and for whom the primary treatment goal is to optimise quality of life. ${ }^{9}$ Demand for palliative care is increasing and has well surpassed a level that can appropriately be provided by hospital-based specialist palliative care services. ${ }^{10,11}$

\section{GPs and home-based palliative care: The three key clinical processes}

GPs have the sentinel role of managing community palliative patients, whether they are living in a private residence or a facility. In the UK, this role has been cemented into routine practice through the introduction of the Gold Standards Framework, which involves evaluation of palliative care needs in general practice. ${ }^{12}$ A simplified framework has been developed in Australia. ${ }^{13}$ There are three key clinical processes within those frameworks that can be easily systematised into practice to guide service delivery, using three essential palliative care elements. 


\section{Identifying patients at risk of} deteriorating and dying (Case, part 1)

Probably the simplest, and surprisingly sensitive, clinical tool for this identification task is the surprise question: 'Would you be surprised if the person died in the next twelve months?' 14

Another useful, though more structured, tool that helps identify people with general indicators of poor or deteriorating health and clinical signs of life-limiting conditions is the Supportive and Palliative Care Indicator Tool (SPICT)..$^{15}$ The SPICT (Figure 1) has gained international acceptance because systematic use encourages clinicians to organise well-coordinated supportive care integrated with appropriate treatment of the person's underlying condition(s).

The surprise question and SPICT can be systematised into the Medicare Health Assessment for Older Persons (75+).

Identification of those at risk of death should trigger or re-instigate comprehensive discussions regarding the person's goals and wishes for care, to inform a future management plan tailored to individual preferences. These iterative discussions are referred to as advance care planning, and discussion outcomes should be documented in a standardised way by the person or their substitute decision maker. ${ }^{16}$

\section{Formulation of a medical 'goals of patient care plan' (Case, part 2)}

While an advance care plan is a patient communication tool, a 'goals of patient care plan' is a medical communication completed by the GP or other doctor. These plans inform other clinicians regarding appropriate responses when the person inevitably deteriorates. ${ }^{17,18}$ They are best completed when it is clinically timely to transition the focus of care from curative or restorative to palliative in intent.

Such a plan translates a person's prior advance care plan into medical treatment orders. ${ }^{17}$ The plan identifies the patient's goals of care and, importantly, matches those with specific medical escalations and limitations of active treatments (such as the provision or withholding of cardiopulmonary resuscitation, de-prescribing or transfer to hospital) proportionate to those goals.

The patient (if possible), their substitute decision maker(s) and other carers (paid and unpaid) should be made aware of the contents of the plan. The plan provides surety of actions in emotionally charged situations and so decreases uncertainty and distress.

\section{Development of a terminal care management plan (Case, part 3)}

When prognosis is limited to the last week or days of life, a shared documented terminal care management plan, focused on regular assessment of patient comfort and relief of carer/ family distress, ${ }^{19}$ is advantageous. Medications to treat common emergent

\section{Supportive and Palliative Care Indicators Tool (SPICT'M)}

The SPICT ${ }^{\mathrm{TM}}$ is used to help identify people whose health is deteriorating.

Assess them for unmet supportive and palliative care needs. Plan care.

Look for any general indicators of poor or deteriorating health.

- Unplanned hospital admission(s).

- Performance status is poor or deteriorating, with limited reversibility.

(eg. The person stays in bed or in a chair for more than half the day.)

- Depends on others for care due to increasing physical and/or mental health problems.

- The person's carer needs more help and support.

- The person has had significant weight loss over the last few months, or remains underweight.

- Persistent symptoms despite optimal treatment of underlying condition(s).

- The person (or family) asks for palliative care; chooses to reduce, stop or not have treatment; or wishes to focus on quality of life.

Look for clinical indicators of one or multiple life-limiting conditions.

\section{Cancer}

Functional ability deteriorating

due to progressive cancer.

Too frail for cancer treatment or treatment is for symptom control.

Dementia/ frailty

Unable to dress, walk or eat without help.

Eating and drinking less; difficulty with swallowing.

Urinary and faecal incontinence.

Not able to communicate by speaking; little social interaction.

Frequent falls; fractured femur.

Recurrent febrile episodes or

infections; aspiration pneumonia.

Neurological disease

Progressive deterioration in physical and/or cognitive function despite optimal therapy.

Speech problems with increasing difficulty communicating and/or progressive difficulty with swallowing.

Recurrent aspiration pneumonia; breathless or respiratory failure.

Persistent paralysis after stroke with significant loss of function and ongoing disability.
Heart/ vascular disease

Heart failure or extensive, untreatable coronary artery disease; with breathlessness or chest pain at rest or on minimal effort.

Severe, inoperable peripheral vascular disease.

Respiratory disease

Severe, chronic lung disease; with breathlessness at rest or on minimal effort between exacerbations.

Persistent hypoxia needing long term oxygen therapy.

Has needed ventilation for respiratory failure or ventilation is contraindicated.

\section{Other conditions}

Deteriorating and at risk of dying with other conditions or complications that are not reversible; any treatment available will have a poor outcome.

Review current care and care planning

- Review current treatment and medication to ensure the person receives optimal care; minimise polypharmacy.

- Consider referral for specialist assessment if symptoms or problems are complex and difficult to manage.

- Agree a current and future care plan with the person and their family. Support family carers.

- Plan ahead early if loss of decision-making capacity is likely.

- Record, communicate and coordinate the care plan.
Figure 1. Supportive and Palliative Care Indicators Tool (SPICT) Reproduced with permission from the SPICT International Programme 
terminal symptoms usually need to be pre-emptively prescribed and charted for later administration by an appropriate route. Carers may need to be taught to manage breakthrough symptoms to avoid unnecessary suffering.

'Death at home' documents - such as standardised form letters stating the person is receiving palliative care or dying an expected death, and not for resuscitation measures but for all comfort cares - are valuable laboursaving resources. When available in the home, this documentation can ensure the person is not inappropriately resuscitated, transferred to hospital or referred to the coroner.

Proactively organising who will write the life extinct form and who will complete the death certificate can avoid after hours call-outs.

\section{GPs and home-based palliative care: Three essential elements for high-quality palliative care}

\section{The compassionate GP}

A compassionate GP empathises with palliative patients and acts to relieve suffering. ${ }^{20}$ Arguably, the single most important role of the compassionate GP in palliative care is to help the person achieve a good death, the 12 principles of which were identified in the final report on The future of health and care of older people (Box 1). ${ }^{21}$

People who are dying and suffering, whether physically, spiritually or

\section{Box 1. Principles of a good death ${ }^{21}$}

- The ability to anticipate death and manage expectations

- Access to any necessary information resources and support, both spiritual and emotional

- Control over the situation, including pain relief, privacy, location of death and individuals present, combined with confidence that any predetermined instructions will be followed

- Maintenance of a sense of dignity

- Avoidance of needless prolonging of life, balanced with adequate time to say goodbye existentially, take great comfort in being supported psychologically and feeling safe. By being their authentic selves, compassionate and empathetic GPs act as a powerful therapeutic tool to promote that outcome.

Most people fear the dying process and do not know what to expect. ${ }^{19}$ Honest, clear and reassuring communication that, with good care and symptom management, most people can die a comfortable death, can help to allay much of that fear.

Carers who have limited experience of death and dying processes also need compassion and support. It is reassuring for them to hear that they are doing a good job in difficult circumstances, particularly if their caring role has been extended to include symptom management and perhaps administration of subcutaneous medicines. To be prepared, they need to know what to expect as death approaches and what to do after death occurs.

\section{The palliative care team}

Palliative care requires a team approach to ensure best patient and carer outcomes. ${ }^{22}$ Most home-based palliative care teams are led and proactively coordinated by the GP. Team members vary and should be determined by patient needs and local availability of professionals. Members include clinicians such as nurses, social workers, occupational therapists, other allied health professionals and the local pharmacist. With more complex patients, specialist palliative care services may be enlisted to complement the skills of the local team.

The carer's role is worthy of mention. Carers usually know the patient most intimately and are motivated to help. Carers are increasingly becoming embedded into resource-stretched palliative care teams to assume some responsibility for symptom management, particularly the preparation and administration of subcutaneous medications. When appropriately educated, they do this safely and with confidence. ${ }^{23,24}$

\section{Available resources}

There are now many freely available practical resources to support GPs to provide high-quality palliative care, some of which are listed in Table 1.

Not all GPs feel motivated to provide palliative care ${ }^{25}$ and so should organise alternative arrangements for their palliative patients.

\section{Conclusion}

Palliative care is team-based care that sits well within the GP specialist scope of practice. Increasingly, GPs will be called on to deliver more palliative care for Australia's growing and ageing population. To meet this demand, GPs can systematise three key clinical processes using three essential elements of palliative care to provide effective, efficient care for homebased palliative patients.

\section{CASE PART 1}

Mary, aged 75 years, lives with her husband, Jack, who is aged 88 years and frail. Mary's comorbidities include atrial fibrillation, diabetes, osteoporosis, arthritis, anxiety and chronic obstructive airways disease (COAD). Despite pulmonary rehabilitation and maximal pharmacotherapy, Mary's COAD is progressively worsening. She has had three unplanned admissions in the past year, recent spirometry results of FEV1/ $\mathrm{FVC}=0.4$, can only mobilise short distances and struggles with activities of daily living. She has lost $4 \mathrm{~kg}$ in the past two months without dieting.

She has an appointment for her Medicare Health Assessment for Older Persons (75+) and attends with her daughter, Ann. Mary went with Ann to a community talk about advance care planning and Mary asks you if this is applicable to her.

You show her a simplified diagram of the Supportive and Palliative Care Indicators Tool and explain that, on the basis of a number of important indicators, her health is worsening. You explain there is no crystal ball to determine anyone's prognosis and that she and her family should talk about choices for her and Jack's care into the future when their health fails.

Two weeks later, Ann brings her parents back for long appointments to 


\section{Table 1. Practical resources to support GP provision of palliative care}

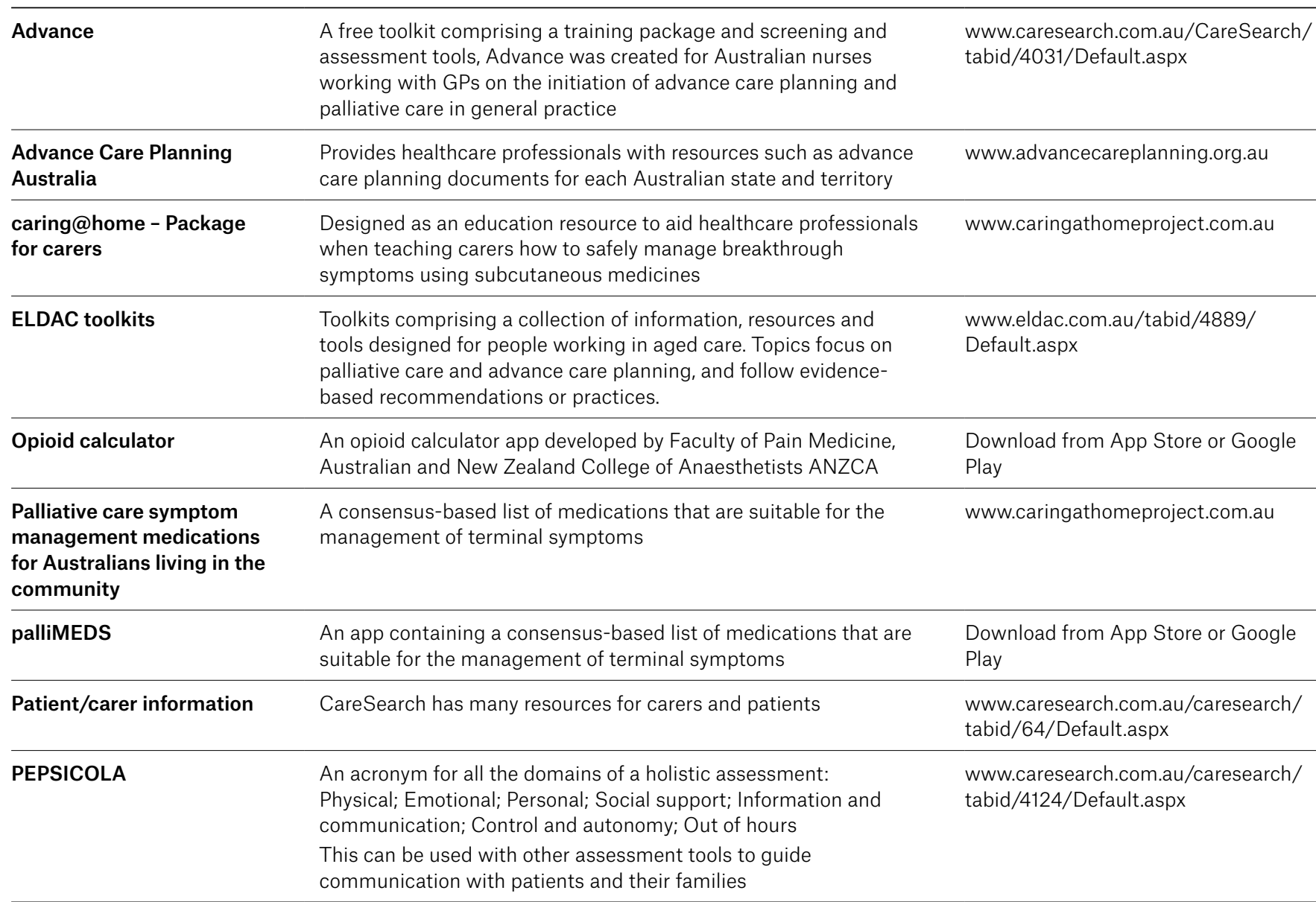

PREPARED An acronym to guide initiating end-of-life discussions with patients and families:

www.racgp.org.au/afp/2010/october/

Prepare for the discussion; Relate to the person; Elicit patient and end-of-life-care/ caregiver responses; Provide information; Acknowledge emotions and concerns; Realistic hope; Document

SPICT

A tool that assists with the identification of people who have a higher risk of deteriorating and dying with one or multiple advanced conditions, thereby improving care planning and palliative care needs assessment

\section{Symptom Assessment Scale (SAS)}

A scale that can be used by clinicians as a checklist or screening tool when reviewing a patient. It can also be used by patients to monitor and report symptoms. www.caresearch.com.au/caresearch/ tabid/3389/Default.aspx discuss their advance care plans. Both want to remain at home for as long as possible and die there, if possible. Ann says she will take time off work to help. Neither want any heroic measures and want to avoid separation, nursing homes and hospital.

You organise home-care nurses, equipment and home help, while
Ann organises meals-on-wheels and investigates care packages through the My Aged Care website.

\section{CASE PART 2}

Two months later, Ann brings Jack to see you urgently. You find that Jack's heart failure is worsening. Jack has increasing breathlessness, marked peripheral oedema and central cyanosis, and cannot sleep supine. Ann reports that, according to Mary, Jack's implantable cardiac defibrillator fired last night. She also reports increasing periods of confusion, though currently he is lucid. There are no apparent reversible causes for his condition. 
You explain that Jack's heart is continuing to fail and that he may not have long to live. You ask Jack if he has changed his mind about any aspects of his advance care plan. He says no, he is tired and wants 'to go', and does not want any further treatment; his only concern is Mary.

You contact Jack's cardiologist to consider having the defibrillator deactivated to avoid unnecessary shocks. You review his medications and prescribe morphine liquid for breathlessness.

Aligning with his wishes, you document a goals of patient care plan. Some particular points regarding Jack's transition from restorative to palliative care include instructions:

- to provide all comfort cares

- not to provide cardiopulmonary resuscitation or invasive ventilation

- not to transfer Jack to hospital

- to only administer intravenous antibiotics or similar measures if consistent with Jack's wishes and best medical practice.

You give Ann a copy of the plan to provide to the ambulance service if required and also provide one for the home-care team and your locum service.

\section{CASE PART 3}

Four months later, Ann requests a home visit for Mary. Mary has been unable to get out of bed for two weeks because of breathlessness, in spite of home oxygen. She needs assistance with all cares and is not interested in food and refusing medications. She complains of tiredness, nausea and ongoing pain in her back and shoulders. She hardly talks at all. Both Mary and Ann are still committed to Mary dying at home, as Jack did.

You visit Mary and make a diagnosis of dying. After reviewing her goals of patient care plan, you:

- arrange with home-care nurses to teach Ann how to manage subcutaneous medications for breakthrough symptom relief using the caring@ home package for carers ${ }^{24}$

- explain that Mary does not need to take her oral medications unless she improves clinically
- prescribe and chart subcutaneous morphine for pain and breathlessness, metoclopramide for nausea and midazolam for anxiety or terminal restlessness

- arrange for the home-care nurses to visit daily and provide Ann with a 24-hour telephone number in case she needs advice

- provide Ann with 'death at home' documentation

- discuss with Ann her impending bereavement and possibilities for support.

You leave a copy of your notes and planned management in Mary's house so that everybody understands the terminal care plan.

\section{Authors}

Liz Reymond MBBS (Hons), PhD, FRACGP, FAChPM, Director, Brisbane South Palliative Care Collaborative, Queensland Health, Qld. Elizabeth.Reymond@health. gld.gov.au

Greg Parker MBBCh, FRACGP, FAChPM, Director, Metro South Palliative Care Service, Queensland Health, Qld

Louisa Gilles BSc, MBBS, FRACGP, DipRANZCOG, General Practitioner, Kenmore Clinics, Brisbane, Qld Karen Cooper BSc (Hons), PhD, Project Manager, Brisbane South Palliative Care Collaborative,

Queensland Health, Qld

Competing interests: None.

Funding: This paper was funded by Brisbane South Palliative Care Collaborative.

Provenance and peer review: Commissioned, externally peer reviewed.

\section{Acknowledgements}

The authors would like to acknowledge the administrative assistance of Ms Myfanwy Fifoot.

\section{References}

1. Palliative Care Australia. Palliative care service development guidelines. Canberra: PCA, January 2018. Available at http://palliativecare.org.au/ wp-content/uploads/dlm_uploads/2018/02/ PalliativeCare-Service-Delivery-2018 web2.pdf [Accessed 29 May 2018].

2. Swerissen H, Duckett S. Dying well. Carlton, Vic: Grattan Institute, 2014. Available at https://grattan. edu.au/wp-content/uploads/2014/09/815-dyingwell.pdf [Accessed 29 May 2018].

3. Australian Bureau of Statistics. Estimates of Aboriginal and Torres Strait Islander Australians, June 2011. Cat no 3238.0.55.001. Canberra: ABS, 2013. Available at www. abs.gov.au/AUSSTATS/abs@.nsf/ Lookup/3238.0.55.001Main+Features1June\%20 2011?OpenDocument [Accessed 29 May 2018].

4. Australian Commission on Safety and Quality in Health Care. Safety and quality of end-oflife care in acute hospitals: A background paper. Sydney: ACSQHC, 2013. Available at www.safetyandquality.gov.au/wp-content/ uploads/2013/09/SAQ083_End_of_life_care V15_FILM_REVISED_TAGGED.pdf [Accessed 29 May 2018].

5. Australian Bureau of Statistics. Causes of death, Australia, 2015. Cat no 3303.0. Canberra: ABS, 2016. Available at www. abs.gov.au/ausstats/abs@.nsf/Lookup/ by\%20Subject/3303.0 2015 Main\%20 Features Australia's\%20leading\%20causes $\% 20$ of\%20death,\%202015 3 [Accessed 29 May 2018].

6. Australian Bureau of Statistics. Deaths, Australia, 2015. Cat no 3302.0. Canberra: ABS, 2016 Available at www.abs.gov.au/Ausstats/abs@. nsf/0/24253FA31435B9D3CA2581A700159 2B7?OpenDocument [Accessed 29 May 2018].

7. Bartel, R. Conversations: Creating choice in end of life care. Melbourne: Australian Centre for Health Research, 2016. Available at www.achr.org.au/ wp-content/uploads/2016/02/ConversationsChoice-in-End-of-Life-Care-ACHR-20161.pdf [Accessed 29 May 2018].

8. Palliative Care Australia. Background report to the palliative care service development guidelines. Melbourne: PCA, 2018. Available at http://palliativecare.org.au/wp-content/ uploads/dlm uploads/2018/02/PalliativeCareBackground-to-Service-Delivery-2018_v3.pdf [Accessed 29 May 2018].

9. Palliative Care Australia. National palliative care standards. 5th edn. Canberra: PCA 2018. Available at http://palliativecare.org.au/ wp-content/uploads/dlm uploads/2018/02/ PalliativeCare-National-Standards-2018_web-3. pdf [Accessed 29 May 2018].

10. Ireland AW. Access to palliative care services during a terminal hospital episode reduces intervention rates and hospital costs: A database study of 19707 elderly patients dying in hospital 2011-2015. Intern Med J 2017;47(5):549-56. doi: 10.1111/imj.13400

11. Senate Community Affairs Committee. Palliative care in Australia. Canberra: Commonwealth of Australia, October 2012. Available at www.aph gov.au/Parliamentary_Business/Committees/ Senate/Community_Affairs/Completed inquiries/2010-13/palliativecare/report/index [Accessed 29 May 2018].

12. National Gold Standards Framework Centre. The gold standards framework. London: GSF, 2018. Available at www.goldstandardsframework.org.uk [Accessed 29 May 2018].

13. Reymond L, Cooper K, Parker D, Chapman M. End-of-life care: Proactive clinical management of older Australians in the community. Aust Fam Physician 2016;45(1):76-78.

14. Lynn J. Living long in fragile health: The new demographics shape end of life care. In: Jennings B, Kaebnick GE, Murray TH, editors. Improving end of life care: Why has it been so difficult? US: The Hastings Center, 2005; p. S14-18. Available at www.thehastingscenter. org/publications-resources/special-reports-2/ improving-end-of-life-care-why-has-it-been-sodifficult [Accessed 1 June 2018].

15. SPICT International Programme. Supportive \& Palliative Care Indicators Tool (SPICT). Edinburgh: SPICT, 2018. Available at www.spict.org.uk [Accessed 1 August 2018].

16. Queensland Government. My care, my choices: Advance care planning. Brisbane: The State of Queensland, 2014. Available at https://metrosouth. health.qld.gov.au/acp [Accessed 29 May 2018].

17. Thomas RL, Zubair MY, Hayes B, Ashby MA. Goals of care: A clinical framework for limitation of medical treatment. Med J Aust 2014;201(8):452-55. 
18. Department of Health and Human Services, Specialist Palliative Care Service. Medical goals of care plan. Hobart: Tasmanian Government, 2018. Available at www.dhhs.tas.gov.au/palliativecare/ health_professionals/goals_of_care [Accessed 1 August 2018].

19. Expert Group for Palliative Care. Palliative Care. In: eTG complete [internet]. Melbourne: Therapeutic Guidelines Limited, 2018.

20. Fernando AT 3rd, Arroll B, Consedine NS. Enhancing compassion in general practice: It's not all about the doctor. Br J Gen Pract 2016;66(648):340-41. doi: 10.3399/ bjgp16X685741.

21. Debate of the Age, Health and Care Study Group. The future of health and care of older people: The best is yet to come. London: Age Concern England, 1999. Available at www.siis. net/documentos/Digitalizados/93461_The\%20 future\%20of\%20healt\%20and\%20care.pdf [Accessed 18 May 2018].

22. Crawford GB, Price SD. Team working: Palliative care as a model of interdisciplinary practice. Med J Aust 2003;179(6 Suppl):S32-34.

23. Healy S, Israel F, Charles MA, Reymond L. An educational package that supports laycarers to safely manage breakthrough subcutaneous injections for home-based palliative care patients: Development and evaluation of a service quality improvement. Palliat Med 2013;27(6):562-70. doi: 10.1177/0269216312464262.

24. Caring at Home Project. caring@home. Brisbane: Brisbane South Palliative Care Collaborative, 2018. Available at www.caringathomeproject.com.au [Accessed 29 May 2018].

25. Rhee JJ, Zwar N, Vagholkar S, Dennis S, Broadbent AM, Mitchell G. Attitudes and barriers to involvement in palliative care by Australian urban general practitioners. J Palliat Med 2008;11(7):980-85. doi: 10.1089/jpm.2007.0251. 